DOI :

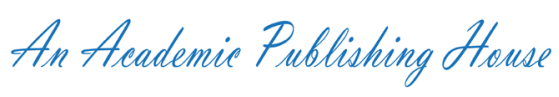

\title{
Advertising Herbal Medicines: On Speech Act Selection and Sequencing
}

\author{
Acheoah John Emike, PhD ${ }^{1}$, Margaret Nonyerem Agu $^{2}$
}

${ }^{1}$ Department of European Languages, Federal University Birnin-Kebbi, Kebbi State, Nigeria.

${ }^{2}$ Department of English, Ibrahim Badamasi Babangida University, Lapai, Niger State, Nigeria.

\begin{abstract}
Research on language use in the advertisement of herbal medicines is quite uncommon. Presently, we do not know of any. This study investigates language use in selected samples of the advertisement of certain herbal medicines. The focus of the study is the functions of speech acts when selected (in terms of categories and frequency) and deployed to achieve intended communicative effects. Hinging on a two-fold theoretical framework (Acheoah's [1] typology of locutionary strategies and Bach and Harnish's [2] speech act taxonomy), this study finds out that: the advertiser's illocutionary goals align with speech acts selection and sequencing; the language is captivating and persuasive; in conveying his message, the advertiser exploits natural human tendencies (aspirations, desires and aversions); and the message is situated in varied social, pragmatic and psychological contexts.
\end{abstract}

KEYWORDS: Advertising, herbal medicine, locutionary strategy, speech act taxonomy

\section{INTRODUCTION}

Adverts are fundamentally meant to promote products. This study investigates the effects that the linguistic dimensions of the advertisement have on the audience and the advertiser's communicative intentions. To understand the meaning of speech acts, it is necessary to underscore their overall situational underpinnings. Speech acts are crucial to human communication. Propositions (such as requesting a person to buy a particular herbal medicine) and social phenomena are conveyed via speech act selection and sequencing. Labove [3] rightly notes that "no use of language can be divorced from its social context since special meaning is parasitic upon language." Without speech act theory, it will be difficult to explain the principles that underpin the encoding and decoding of utterances; the normative rules of language cannot account for the intentions, attitudes, and other dynamics of human communication. To investigate the communicative implications of speech act selection and sequencing in the advertisement of herbal medicines, this study uses selected samples of a recorded advertisement of herbal products as a case study. The advertiser advertised the products by using a loudspeaker, and this is typical in busy commercial parts of Nigeria.

\section{SPEECH ACT}

When the early scholars of pragmatics evolved theories of the discipline, they realised that the minimal unit of communication is not the sentence, but acts (actions) performed by using such sentences in various contexts of communication: giving orders, advising, apologising, persuading, informing, etc. This explains why Alston, cited in David A. Brenders [4] asserts that "The correct unit of analysis for meaning is not at the level of words since, referring or denoting is something one does in the course of performing a larger action-unit, such as making a request, admission, or prediction."

As a pioneer scholar of speech act theory, Austin [5] classified speech act into three types: locutionary act (performing an act OF saying something); illocutionary act (performing an act IN saying something); and perlocutionary act (performing an act BY saying something). Searle, cited in Brenders [4] opines that "in the performance of an illocutionary act the speaker intends to produce a certain effect by means of getting the hearer to recognize his intention to produce that effect, and furthermore, if he is using words literally, he intends this recognition to be achieved ..." Austin notes that speech acts can be performed by using a non-performative formula. David A. Brenders [4] posits that "Speech act theory, as a part of the philosophy of language, has been concerned with analyzing the performance of linguistic acts (asserting, promising, questioning) as a rule-governed form of behaviour..."

Research on speech acts continues to be springboard 
for the analysis of language use across genres. This view corroborates Pratt [6] who avers that "Speech act theory provides a way of talking about utterances not only in terms of their surface grammatical properties but also in terms of the context in which they are made, the intentions, attitudes, and expectations of the participants, the relationships existing between participants ... rules and conventions that are understood to be in play when an utterance is made and received." Significant efforts on speech act taxonomy (categorisation) abound in the literature. In this regard, Austin [5], Searle [7] and Bach and Harnish [2] are instructive.

\section{THEORETICAL FRAMEWORK}

For the analysis of data, this study hinges on Bach and Harnish [2] and Acheoah [1]:

\section{Bach and Harnish (1979)}

Bach and Harnish [2] is relevant to this study in terms of its stance on: shared knowledge and speech act classification (taxonomy). Their approach to speech act is based on intention and inference. They contend that for speakers to perform illocutionary acts, it is intended that their listeners have the understanding of the acts (mutual contextual beliefs). They contend that conversation (interactional talk) involves an inferential process. Their terminology, "Speech Act Schemata" (SAS) refers to an inevitable part of the inferential process in a communicative event. They strongly posit that speaker-hearer mutual contextual beliefs (MCBs) facilitate the inferential process. To infer what $S$ is saying, the hearer $(\mathrm{H})$ depends also on the "Presumption of Literalness" (PL); the hearer should know when the linguistic communication of the speaker $(\mathrm{S})$ is within or outside the bounds of literalness, and if $S$ is speaking in a non-literal dimension, $\mathrm{H}$ should not only acknowledge it, but should also be able to understand what such speech by $\mathrm{S}$ means. Apart from MCBs, Bach and Harnish [2] recognize other types of beliefs shared by an entire linguistic community, which the hearer relies on for inference-making:

(i) Linguistic Presumption (LP); and

(ii) Communicative Presumption (CP).

Linguistic Presumption (LP) refers to the moral belief that members of a Linguistic Community (LC) share on the particular language (L). Therefore, any expression (e) uttered by a member to any member of the community, is taken by the speaker for granted; the speaker presupposes that the hearer understands the expression or utterance. An act of communication is successful as soon as the hearer recognizes the speaker's illocutionary intention.

Bach and Harnish [2] recognize two broad categories of illocutionary acts: communicative and non-communicative. While the former requires the recognition of S's R-intention, the latter does not. In their theory, there are four main categories of communicative illocutionary acts: Constatives, Directives, Commissives and Acknowledgements. These four main categories correspond rougly to Austin's Expositives, Exercitives, Commissives, and Behabitives respectively and closely to Searle's Representatives (Assertives), Directives, Commissives and Expressives, differing mainly in their characterizations. There are two classes of noncommunicative illocutionary acts: Effectives and Verdictives, corresponding roughly to Searle's [7] Declarations. A detailed account of the categories established by them are speech acts which express the speaker's belief and intention, or, at least the implication or desire, that the hearer form (or continue to hold) a like belief. Fifteen subcategories of this group are recognized as follows: Assertives, Informatives, Confirmatives, Concessives, Retractives, Assentives, Dissentives, Disputatives, Responsives, Suggestives and Suppositives.

Assertives are characterized by S's expression of belief that the hearer $(\mathrm{H})$ also believes that P. Examples of verbs denoting Assertives are: affirm, allege, assert, aver, avow, declare, and deny.

Informatives are speech acts in which $\mathrm{S}$ expresses "the belief that P" and also "the intention that $\mathrm{H}$ form the belief that P". Examples are advise, announce, appraise, disclose, inform, insist, notify, point out, report, reveal, tell, and testify.

In Descriptives, the speaker declares that "a particular quality is possessed by a person, place or thing"; the speaker expresses "the belief that $\mathrm{O}$ is $\mathrm{F}$ " and "the intention that $\mathrm{H}$ believes that $O$ is F". Examples are appraise, asses, call, categorize, characterize, classify, date, describe, diagnose, evaluate, etc.

Directives express the speaker's attitude toward a future action by the hearer and the speaker's intention or desire that the hearer considers his utterance as reason to act. Six subcategories of illocutionary acts are listed under this category: Requestives, Questions, Requirements, Prohibitives, Permissives, Advisories.

Questions are "special cases of requests; the hearer is requested to provide the speaker with certain information. A speech act is considered a question if S expresses "the desire that $\mathrm{H}$ tell $\mathrm{S}$ whether or not $\mathrm{P}$ " and "intention that $\mathrm{H}$ tell $\mathrm{S}$ whether or not P because of S's desire". Examples are: ask, interrogate, query, questions, quiz, etc.

Advisories express the belief that "there is (sufficient) reason for $\mathrm{H}$ to A (act)" and "the intention that $\mathrm{H}$ takes S's belief as (sufficient) reason for him to A". Examples are: advise, caution, counsel, propose, recommend, suggest, urge, warn, etc.

Commissives involve "the undertaking of an obligation or proposal to undertake an obligation". Two main types of this category are distinguished: Promises and Offers. S promises $\mathrm{H}$ to $A$ if $S$ expresses "the belief that his utterance obligates him to A", "the intention to A", and "the intention that $\mathrm{H}$ believes that S's utterance obligates S to A and that S intends to A". See the theory for more insights on speech act categories and the verbs that denote them. 


\section{Acheoah's Typology of Illocutionary Strategies}

Acheoah [1] evolves a typology of illocutionary strategies. Predating speech act theories evolve broad categories of speech acts e.g. Assertives, Ascriptives Informatives, Verdictives, etc. The theories do not investigate speech acts in terms of the discrete forms that illocutionary acts take in discourse. Acheoah's [1] typology reveals different forms of illocutionary acts informed by speaker-meaning. For example, to state the price of a particular herbal medicine, the advertiser can deploy Informatives that capture Strategy Eight (making an ironical remark) in Acheoah's [1] typology. In this section of the paper, we mention just a few of the illocutionary strategies. For the purpose of this study, we simply state the locutionary and illocutionary acts of the strategies that are relevant to this study. For tips on the other illocutionary strategies in the theory, and the pragmatic features that underpin their use, see Acheoah [1]:

\section{Strategy Two: Ascribing quality to the object requested}

Locutionary Act: Even little money settles disputes.

Illocutionary Act: to request money from $\mathrm{H}$

Strategy Three: Using a constituent to demand a whole

Locutionary Act: You are the Guest Speaker for the Conference.

Illocutionary Act: inducing $\mathrm{H}$ to attend the conference

Strategy Four: Offering to do what $\mathrm{H}$ will not accept

Locutionary Act: Let me get to the back seat.

Illocutionary Act: inducing $\mathrm{H}$ to go to the back seat

Strategy Six: Declaring what $\mathbf{H}$ will not do if he possesses a certain quality

Locutionary Act: A responsible father will not abandon his family.

Illocutionary Act: requesting $\mathrm{H}$ to desist from an action/ attitude

\section{Strategy Seven: Mentioning a constitutive referent}

Locutionary Act: Omoba is in Ise Shrine.

Illocutionary Act: to inform $\mathrm{H}$ that they had arrived in Etsako, Edo State

\section{Strategy Eight: Making an ironical remark}

Locutionary Act: The footballer is so skillful that he could not score even a single goal throughout the tournament.

Illocutionary Act: rejecting the claim that the footballer is skillful

\section{METHODOLOGY}

Data for analysis in this study are selected based on two basic parameters: clarity of message and quality of pragmatic (speech acts) features. As mentioned already, they are divided into utterances (a1-f31) with each utterance reflecting its speech act category or categories. Via tabular representation, the speech acts used by the advertiser are shown in terms of frequency and functions.

\section{Presentation of Data}

The six samples of adverts selected for analysis are as follows:

a. You wake up every morning and tell madam that you are weak.

b. Tisol 100 is the answer. You are always too tired to go to your place of work, but you have to win the family's bread.

c. The powder in a cup of water is all you need to bring down the mountain.

d. Waist pain must not kill you. For how long have you been suffering it? There is a remedy.

e. You were even thinking that there is no cure for the yamayama. Country people, never mind. Only one dose.

f. Sometimes when you talk, people will close their mouths because of the pleasant aroma from your mouth. My brother, my sister, your mouth is not latrine. Stop disgracing yourself. God did not create you so. Roka mouth cleanser is what you need. When you get home, take it twice a day. Only three days experience, you will come for more. There are no side-effects. There is no need for overdose. Return it if you are disappointed. In fact, come and have it free of charge and you will ask for more. You remember Oliver Twist?

Nobody wants to die. Who does not want to live long? It is seven hundred naira for one bottle. It is called herbal flush. As it is thick, that is how it works. Purify your blood. Be strong. Dizziness is a problem. Empty a cover of the liquid into a cup of tea, water or pap. Stair it and drink three times daily before meal.

The above data are divided into utterances (henceforth $a_{1}$ $a_{31}$ ) for ease of reference and analysis:

$a_{1}$ : You wake up every morning and tell madam that you are weak. (Assertive, Ascriptive)

$a_{2}$ : Tisol 100 is the answer. (Informative, Requestive) $a_{3}:$ You are always too tired to go to your place of work, but you have to win the family's bread. (Requestive, Assertive)

$b_{4}:$ The powder in a cup of water is all you need to bring down the mountain. (Informative) 
$c_{5}$ : Waist pain must not kill you. (Dissentive, Requestive)

$c_{6}$ : For how long have you been suffering it? (Question)

$c_{7}$ : There is a remedy. (Informative)

$d_{8}:$ You were even thinking that there is no cure for the yamayama. (Assertive, Declaration)

$d_{9}$ : Country people, never mind. Only one dose... (Informative, Requestive)

$e_{10}:$ Sometimes, when you talk, people will close their mouths because of the pleasant aroma from your mouth. (Declaration, Assertive, Dissentive)

$e_{11}:$ My brother, your mouth is not latrine. (Dissentive, Assertive, Declaration)

$e_{12}:$ Stop disgracing yourself. (Requestive, Dissentive)

$e_{13}:$ God did not create you so. (Assertive, Informative, Declaration)

$e_{14}$ : Roka mouth cleanser is whatyou need. (Requestive, Informative)

$e_{15}$ : When you get home, take it twice a day (Informative, Requestive)

$e_{16}$ : Only three days experience, you will come for more. (Informative)

$e_{17}:$ There are no side-effects. (Informative)

$e_{18}$ : There is no need for overdose. (Informative, Requestive)

$e_{19}:$ Return it if you are disappointed. (Informative, Requestive)

$e_{20}:$ In fact, come and have it free of charge and you will ask for more. (Informative, Requestive, Offer)

$e_{21}:$ You remember Oliver Twist? (Question, Ascriptive)

$f_{22}:$ Nobody wants to die. (Declaration, Assertive)

$f_{23}$ : Who does not want to live long? (Question)

$f_{24}$ : Seven hundred naira for one bottle. (Informative)

$f_{25}$ : It is called herbal flush. (Informative)

$f_{26}$ : As it is thick, that is how it works. (Informative, Ascriptive)

$f_{27}$ : Purify your blood. (Requestive)

$f_{28}$ : Be strong. (Requestive, Ascriptive)

$f_{29}$ : Dizziness is a problem (Assertive)

$f_{30}$ : Empty a cover of the liquid into a cup of tea, water or pap. (Informative, Requestive) $f_{31}$ : Stair it and drink three times daily before meal. (Informative, Requestive)

\section{ANALYSIS}

In this section of the paper, we present an integrative analysis of the discourse.

\section{Sample (a)}

The contextual structure (domain) of $a_{1}-a_{3}$ is family setting (home) where a husband is expected to perform his conjugal obligations to his wife; the advertiser is aware of the norms and values of the human society within the context of marriage (world knowledge). It is therefore not incidental, that the advertiser chooses "morning" for the predication. The advertiser is aware that there are negative implications if a husband does not fulfill his conjugal obligations; it can result in divorce or infidelity. In this text, the advertiser uses Strategy Three of Acheoah's [1] illocutionary act typology (using a constituent to demand a whole); winning the family's bread entails being well (having good health). The addressees understand that the advertiser links the product to their wellbeing. Indeed, advertisers deploy their knowledge of society to communicate to society. Being part of society, they share with other people, the psychological state(s) expressed in/by an utterance. The product (Tisol 100) is advertised as a confirmed solution to a seemingly age-long problem as the expression "every morning" has the potential to establish an unspecified backward duration of the condition predicated. The use of "win" is thought-provoking and inspirational. No one wants to lose a battle; however, winning entails paying a price. The hearer understands the expression "bread" as a whole range of food items that can sustain a family. By implication (conversational implicature), Tisol 100 can give the user health to provide what will sustain the family. See Grice [8] for tips on the categories of implicature.

We posit that $a 1$ and $a 3$ capture Strategy Six of Acheoah's [1] illocutionary act typology (declaring what $\mathrm{H}$ will not do if he possesses a certain quality). In $a 1$, the advertiser implies that the addressee is too weak to perform his conjugal duty to his wife. Similarly, in $a 3$, the advertiser talks about "being too tired" as the addressee's reason for "not being able to go to the place of work". Interestingly, a1 and $a 3$ also deploy Strategy Six. The utterances conveyed imply that the addressee will not find it difficult to perform the actions if they are strong (in good health).

\section{Sample (b)}

A vivid description of the medicine is given in $b_{4}$. The addressees explore their world knowledge (shared knowledge) about the different forms of orthodox medication, to understand $b_{4}$; they know that medicines can be packaged in different forms: capsules, tablets, liquid or powder. In the text, "mountain" is a metaphor for "any serious disease/ illness". Since the disease or sickness is not mentioned in $b_{4^{\prime}}$ it can be inferred that the advertiser had mentioned it earlier. 
By claiming that a cup of water containing the powder is enough to cure the disease/illness, the advertiser makes the potency of the product alluring to the audience - a singledose therapy for a worrisome disease is worth rushing to buy. The use of the expression "mountain" gives the audience an impression that the medicine is efficacious even in the treatment of long time illnesses.

\section{Sample (c)}

Indeed, $c_{5}-c_{7}$ show that in the advertisement of herbal medicines, the "topic relevance" is essentially "health". The advertiser directly mentions the topic of discourse, using a modal auxiliary (must) that presents the product as being much more powerful than the sickness - a very potent communicative device that makes the audience have confidence on the product. The advertiser makes the audience ponder on life and death, and then use their rational thinking to choose life. The rhetorical question is captivating; the advertiser uses it to relegate the sickness (waist pain), and magnify the product (Tisol 100). The utterance $\left(c_{6}\right)$ has secondary and primary illocutionary act potentials. Its primary illocutionary act is "the product will cure waist pain no matter how long it had been" - although the product is not mentioned in the utterance. Advertisers of herbal medicines attempt to play on their audience's emotions by focusing their language on the description of the products in terms of property and efficacy. This strategy makes the audience anxious to know the name of the products and use it (patronage). The declaration "There is a remedy" intensifies the audience's desire for the product.

\section{Sample (d)}

The topic relevance of $d_{8}$ and $d_{9}$ is our shared knowledge of how people who experience prolonged illness end up thinking that there is no cure for it (psychological context). Advertisers of herbal medicines explore their consciousness of the human mind and articulate such consciousness in their adverts. The language they deploy does not operate in a vacuum; it is informed by the advertisers' beliefs about human desires. The declaration $\left(d_{8}\right)$ seems to put advertisers in the position of soothsayers who see the past and future. This is the reason why people patronize them, and the advertiser seeks such patronage. The use of Nigerian Pidgin in the text is not incidental; Nigerian Pidgin is deployed for effective communication because of its socio-cultural underpinnings. In this regard, yamayama is a cover-term for all illnesses: waist pain, diabetes, headache, malaria, ulcer, etc. Many herbal medicines are known for their multiple functions, unlike many orthodox medicines. Nigerian Pidgin cuts across social class, and advertisers of herbal medicines explore this attribute towards persuasive communication of message. In $d_{g^{\prime}}$ the pronoun "you" does not specify the referent - it refers to "whoever" is listening to the on-going advertisement. This devise is attention-getting, thus opening the advertiser's door to everybody.

\section{Sample (e)}

A very shameful situation is ironically depicted in $e_{10}$; the sufferer of the illness is stigmatized. Strategy Eight (making an ironical remark) as in Acheoah [1] is demonstrated here as the expression "aroma" is used sarcastically. Even if the audience's situation is not as bad as that depicted, the advertiser's strategy of depicting a stigmatized extreme is worrisome to the audience. People want to integrate with their fellow human beings in different domains of society. Nobody wants to be avoided as a plague. The fact that the addressees believe that "prevention is better than cure", is enough to make them buy the product, and use it. The use of the expressions "brother" and "sister" make the audience know that the medicine is generally good for humans. The referent "latrine" helps the advertiser to communicate the seriousness of the illness. We contend that effective use of language for the advertisement of herbal medicines, like in the advertisement of other products, enables the audience to pick referents from the universe of discourse as they process utterances to derive topic relevance. By using imageconjuring expressions, advertisers talk less but communicate more. For example, "latrine" is used connotatively (contextually) rather than denotatively. The listeners already know that God did not create them with an offensive mouth ordour, yet the advertiser reminds them of this fact so as to establish good-evil effect which gives the product some aura of supernatural and superlative spiritual essence and approval. This impinges on the audience's approval of the product. From our world knowledge of orthodox treatment of minor illnesses, patients are often given three days to use a medicine after which they are advised to see their doctors if the efficacy of the medicine is not noticed. It can be deduced from the text that advertisers of herbal medicines sometimes use orthodox standards in their descriptions and prescriptions. In this datum, the advertiser uses a modal auxiliary that conveys "certainty" ("will" in $e_{16}$ ). Naturally, people want to be convinced about the efficacy of any medicine; therefore, the use of "will" is very appropriate. Even though certain medicines are efficacious, people do not use such medicines owing to their side-effects. In this text, it is obvious that the advertiser explores his knowledge of people's attitude towards the side-effects of medicines (world knowledge). However, the advertiser uses an Informative to dislodge the audience's possible fears. Essentially, $e_{17}-e_{18}$ are short utterances that give the audience useful information about the medicine, and also request their patronage (by implication). Like $a 2$ and $b 4, e 16$ and other structures deploy Strategy Two as in Acheoah [1] (ascribing quality to the object requested); in this context, the object requested is that for which patronage is requested (Tisol 100). From $e_{20}$ and $e_{21}$, we see that advertisers sometimes deploy comic elements to gain the attention of their audience. It is comic for a seller who wants to make profits to be the one telling prospective buyers that his products are free of charge. The advertiser explores Strategy Four of Acheoah's [1] illocutionary act 
typology (offering to do what $\mathrm{H}$ will not accept). Possibly, some of the listeners are aware of the connotative meanings often attached to the literature character, Oliver Twist - in a famous literary text, Oliver Twist asked for more (meal).

\section{Sample (f)}

To foster textual cohesion, "die" and "live" are used in declarative and interrogative clauses respectively. As opposite words (antonyms), when "die" and "live" echo each other. That is, when a listener hears the word "die", "live" echoes in the mind. Advertisers subtly engage their audience in logical reasoning, and sustain this strategy for optimal commercial benefits. Although $f_{22}-f_{25}$ are short utterances, they are communicatively effective. The advertiser understands that since many of his addressees are pedestrians who are rushing to get to their places of work or to other places, it is necessary to convey condensed but complete message about the medicine being advertised. In the text, the expression "thick" $\left(f_{26}\right)$ is used because people often attribute the thickness of a substance to its quality. Given the fact that blood is life, the listeners are pleased to hear that the product can purify blood. The advertiser consistently deploys antonyms - some of which are merely equivalent words rather than being conventional antonyms. For example, "die" and "live" are perfectly antonymous. Similarly, "strong" and "weak" are perfect antonyms. However, in terms of antonymous sense relation, "strong" $\left(f_{28}\right)$ and "dizziness" $\left(f_{29}\right)$ are mere equivalents because there is a sense in which one means the other. Indeed, $f_{20}$ and $f_{21}$ show that advertisers of herbal medicines do not only concentrate on stating the functions of their medicines, but also give information on how the medicines are used. Advertisers use different strategies to ensure that they capture different categories of buyers. For example, "tea", "water" and "pap" are used so that the addressees will hardly have any excuse for not willing to buy the medicine. Some people do not like taking pap, and this is enough to discourage them from buying the medicine if the advertiser had said the medicine can only be taken with pap.

\section{DISCUSSION}

Advertisers of herbal medicine explore the background information they have about their audience, and relate such information with what they say about their products. The background assumption of any communication event (shared knowledge) is essentially the presupposition(s) about the context. Through the use of discrete illocutionary strategies, advertisers of herbal medicines convey shared knowledge and context-driven meanings. According to Savas L. T. [9], "the study of illocutionary act should be acknowledged as an indispensable component of the study of meaning." If the addressees know the illocutionary act performed in an utterance uttered by the advertiser, they will definitely understand the advertiser's communicative intention. The intentional nature of illocutionary acts is captured by David Harrah, cited in Savas L. T. [9] who notes that "most speech acts seem to be focused and directed. They are intended as coming from the agent and going to the receivers or audience. They are intended to have a certain point, and they are intended to be construed as having a certain point." In a similar vein, Faigenbaum [10] posits that "the meaning of the sentence is its use in the speech act ... speaker meaning is a matter of the intentional content." Thus, mastery of speech acts in terms of typology (linguistic competence) is instrumental in pragmatic use of locutionary acts (communicative competence) in the advertisement of herbal medicines.

The analysis done in this study shows that the meanings conveyed by each speech act category (illocutionary act) is a reflection of the advertiser's communicative. Consider Table 1 :

Table 1. Speech Act Selection and Sequencing in the Advert

Table 1 above shows the speech act selection and sequencing deployed by the advertiser. The frequency and percentage are instructively captured. Each speech act category performs one or more functions in the discourse:

\begin{tabular}{|c|c|c|c|}
\hline Speech Act Category & Frequency & Percentage & Function \\
\hline Declaration & 5 & $9.8 \%$ & $\begin{array}{l}\text { - to make statements about the audience, the medicine and related } \\
\text { phenomena }\end{array}$ \\
\hline Informative & 13 & $25.5 \%$ & $\begin{array}{l}\text { - } \quad \text { to perform multiple speech acts (informing, requesting, persuading, } \\
\text { advising and instructing); } \\
\text { - } \quad \text { to introduce the medicine and state its use and efficacy; } \\
\text { - } \quad \text { to mention the price of the medicine; } \\
\text { - } \quad \text { used as the Master Speech Act of the discourse (see Adegbija [11] } \\
\text { for tips on the term "Master Speech Act"); }\end{array}$ \\
\hline Dissentive & 3 & $5.9 \%$ & - to reject sicknesses and their consequences on the audience \\
\hline Ascriptive & 4 & $7.9 \%$ & $\begin{array}{l}\text { - } \quad \text { to state the qualities that make the medicine good for the prospective } \\
\text { buyers; } \\
\text { - } \quad \text { to describe the effects of good or bad health on the sufferers }\end{array}$ \\
\hline Offer & 1 & $1.9 \%$ & - to get the audience's attention and patronage \\
\hline
\end{tabular}




\begin{tabular}{|l|l|l|l|}
\hline Assertive & 8 & $15.7 \%$ & - as used in Declarations \\
\hline Requestive & 14 & $27.5 \%$ & $\begin{array}{l}- \text { to give instructions on how the medicine should be used; } \\
- \text { to request (seek) patronage }\end{array}$ \\
\hline Question & 3 & $5.9 \%$ & - to convince the audience that good health is non-negotiable \\
\hline
\end{tabular}

\section{CONCLUSION}

Speech acts have persuasive potential when deployed in the advertisement of herbal medicines. For example, Informatives and Declaration translate to being used to convince the audience about the suitability and efficacy of the product. The language is skillfully deployed to achieve the advertiser's communicative intentions as Informatives are used to manipulate the audience's impression about the product. The Master Speech Act of the entire discourse is Requestive (27.5\%), and this is because the major purpose of commercial adverts is to request patronage. It is The locutionary strategies deployed by the advertiser include: articulating speaker-hearer shared knowledge, mentioning a constitutive referent; ascribing quality to the object requested; offering to do what $H$ (the hearer) will not accept; declaring what $\mathrm{H}$ will not do if he possesses a certain quality. This study shows that indeed, more research is needed on the instrumentality of speech act selection and sequencing in the advertisement of medicinal products in general.

\section{REFERENCES}

1. Acheoah, J. E. (2018). Towards a typology of illocutionary strategies: A case study of selected Nigerian film discourses". Bulletin of Advanced English Studies, 1(2): 150-159.

2. Bach, K. \& Harnish, R. (1979). Linguistic communication and speech acts. Cambridge, Massachusetts. The MIT Press.
3. Labov, W. (1972). The study of language in its social context. Ed. Pier Paolo

4. Brenders, D. A. (1982). Fallacies in the coordinated management of meaning: A philosophy of language critique of the HeirachicalOrganaization of Coherent Conversation and Related Theory. Quarterly Journal of Speech 73:329-348.

5. Austin, J. (1962). How to do things with words. Cambridge: Harvard University Press.

6. Pratt, M. (1977). Towards a speech act theory of literary discourse. Bloomington: Indiana University Press.

7. Searle, J. (1969). Speech acts: An essay in the philosophy of language. New York: Cambridge University Press.

8. Grice, H. P. (1975). "Logic and conversation.” In Cole and Morgan. (eds.)

9. Savas, L.T. ed. (1994). Foundations of speech act theory. London: Routledge.

10. Faigenbaum, Gutavo. (2003). Conversation with John Searle. Montevideo: Libros En Red.

11. Adegbija, E. F. (ed.) (1999). The English language and literature in English: An introductory handbook. Ilorin: University of Ilorin.

Citation: Acheoah John Emike, Margaret Nonyerem Agu, “Advertising Herbal Medicines: On Speech Act Selection and Sequencing", American Research Journal of English and Literature, Vol 7, no. 1, 2021, pp. 1-7.

Copyright (C) 2021 Acheoah John Emike, Margaret Nonyerem Agu, This is an open access article distributed under the Creative Commons Attribution License, which permits unrestricted use, distribution, and reproduction in any medium, provided the original work is properly cited. 